\title{
Coronavirus Disease 2019 (COVID-19); Perspective of Pakistan
}

\section{Tauseef Ahmad ${ }^{1 *}\left(\mathbb{D}\right.$, Muhammad Waseem Shah ${ }^{2 \#}\left(\mathbb{D}\right.$, Hussain Ahmad $^{3 \#}$ and Muhammad Khan ${ }^{4 \#}$}

${ }^{1}$ Department of Epidemiology and Health Statistics, School of Public Health, Southeast University, Nanjing, (210009), China. 'Department of Nutrition and Food Hygiene, School of Public Health, Southeast University, Nanjing, 210000, China. ${ }^{3}$ The Key Laboratory of Biomedical Information Engineering, Ministry of Education School of Life Sciences and Technology, Xi'an Jiaotong University, Xian, China. ${ }^{4}$ Department of Genetics, Centre for Human Genetics, Hazara University Mansehra, Khyber Pakhtunkhwa, Islamic Republic of Pakistan.

*Correspondence: tahmad@seu.edu.cn; "These authors contributed equally.

(Received: April 06, 2020; accepted: May 02, 2020)

Citation: Ahmad T, Shah MW, Ahmad H, Khan M. Coronavirus Disease 2019 (COVID-19); Perspective of Pakistan, J Pure Appl Microbiol. 2020;14(suppl 1):699-701. doi: 10.22207/JPAM.14.SPL1.03

(c) The Author(s) 2020. Open Access. This article is distributed under the terms of the Creative Commons Attribution 4.0 International License which permits unrestricted use, sharing, distribution, and reproduction in any medium, provided you give appropriate credit to the original author(s) and the source, provide a link to the Creative Commons license, and indicate if changes were made. 


\section{INTRODUCTION}

Coronaviruses (CoV) are a group of seven viruses that cause ailment extending from the common sickness to extreme illnesses. Which include Human coronavirus 229E (HCoV229E), Human coronavirus OC43 (HCoV-OC43), Human coronavirus NL63 (HCoV-NL63), and Human coronavirus-HKU1 (HCoV-HKU1) cause mild infections. While Severe acute respiratory syndrome coronavirus (SARS-CoV), Middle East respiratory syndrome coronavirus (MERS-CoV), and Severe acute respiratory syndrome coronavirus-2 (SARS-CoV-2) cause severe infections in human ${ }^{1}$. The disease caused by SARS-CoV-2 known as Coronavirus Disease 2019 (COVID-19). A mild symptom to severe illness and death is being reported in the confirmed cases of COVID-19 and main symptoms include fever, cough, and dyspnea. According to the Center for Disease Control and Prevention (CDC), symptoms may appear within 2 to 14 days after exposure based on the incubation period of MERS-CoV viruses ${ }^{2}$. SARS-CoV-2 rapidly transmit from human to human ${ }^{3}$.

The World Health Organisation (WHO) declared COVID-19 as pandemic after the cases have been increased with an alarming rate across the globe. All the continents are suffering from COVID-19 pandemic except Antarctica, which has few people in the whole continent that stay only in the research station established at Antarctica. COVID-19 pandemic has adversely affected all the fields of life and its effects will remain for years. Developing countries like Pakistan which has a low economy will be affected more due to the lockdown. The common people will suffer more as the majority of people rely on daily wages. So the longterm lockdown may lead to crises. WHO has predicted that the epicenter of COVID-19 may be shifted from West to South East Asia. WHO has warned that if the Republic of India, the Islamic Republic of Pakistan and the Islamic Republic of Afghanistan have not taken it seriously then these countries will suffer more than the developed countries being unprivileged in health infrastructure. In both, India and Pakistan the confirmed cases and resulted deaths are increasing rapidly. Although, the number of reported cases from both countries are low because of low per capita testing capacity. Lack of diagnostic facilities at large may lead to increase the number of patients and hence it can lead to a stage where the hospital will have no space for the severe patients which may result in huge mortalities.

\section{COVID-19 cases in Pakistan}

The first case of COVID-19 in Pakistan was detected and officially notified on $26^{\text {th }}$, February 2020. The travel history of the first two patients revealed that both came from Iran. While the first mortality occurs at Mardan City of Khyber Pakhtunkhwa province, and the travel history showed that he got infected in Kingdom of Saudi Arabia and then traveled back to Pakistan. Mostly COVID-19 infected people came from Iran, Saudi Arabia, United Sates of America and China. As the health system of the country was not fully equipped to respond the pandemic effectively, so the infected people went back to their homes rather they get quarantine at allocated places to stop the spread of COVID-19. In Pakistan, as of May 02, 2020 (01:35pm Pakistan Standard Time), a total number of confirmed cases reached to 18,114 with $417(2.30 \%)$ deaths. The global number of cases have been increased with alarming rate and crossed 3.3 million figures with 238,796 (7.14 \%) deaths ${ }^{4}$.

\section{Government response}

The movement from China and Iran to Pakistan is very frequent. Since both the neighbouring countries of Pakistan are badly affected with the COVID-19, it was quite expected for Pakistan to get COVID-19 cases at any time. Developing countries like Pakistan has a big challenge to strengthen COVID-19 pandemic preparedness due to limited financial and technical resources. It has been observed that during the past infectious disease's outbreaks in Pakistan, thousands of mortalities were reported. When COVID-19 cases have been reported in Pakistan, it seems that Pakistan was not wellprepared in term of medical supplies, diagnosis and screening at airports. The screening at airports was low and not a standard one that time, otherwise diagnosed patients should have been detected and quarantined once they landed at the airports. In the light of such experiences and history, it is a very alarming situation for the whole country. Pakistan government has imposed the lockdown for 3 weeks. Currently, a partial 
lockdown has been announced. But cases keep increasing day-by-day, and people are not taking preventive measures in most of the urban and rural areas of Pakistan.

Future recommendations

The infected individuals came from different countries. In an earlier study, we suggested that Pakistan should impose very strict regulations on the entry points and every traveler should get quarantined otherwise COVID-19 will spread across the country ${ }^{5}$. Strict regulations were not imposed at airports which lead to bring the infection through the travelers. There is a dire need to put strict screening at airports as well as all the people who came from the infected countries should be quarantined for 14 days as per the given instructions by the WHO. Following steps should be taken by the Government in order to control the transmission of COVID-19 in Pakistan.

Massive screening and diagnosis is crucial to identify and quantify infected individuals. Although some provinces like Sindh is carrying out the diagnosis massively while the biggest populated province, Punjab has very low diagnosis ratio which may lead to crises.

A quick and rapid front line force should prepare which will identify all the contacts and individuals who came in contact with infected individuals before diagnosis.

Diagnosis facility and test report timing should be improved in order to shift the infected individual to quarantine quickly.

A strict lockdown should be imposed in the areas where COVID-19 cases have been identified to control the transmission of the disease to healthy individuals.

\section{ACKNOWLEDGMENTS}

All the authors acknowledge their respective universities.

\section{CONFLICT OF INTEREST}

The listed author(s) declare no conflict of interest in any capacity, including competing or financial.

\section{AUTHORS' CONTRIBUTION}

Study design: TA; Writing, edited and review: TA, MWS, HA and MK.

\section{FUNDING}

None.

\section{ETHICS STATEMENT}

This article does not contain any studies with human participants or animals performed by any of the authors.

\section{AVAILABILITY OF DATA}

Not applicable.

\section{REFERENCES}

1. National Institute of Allergy and Infectious Diseases (NIAID). COVID-19 is an emerging, rapidly evolving situation. Available from: https://www.niaid.nih.gov/ diseases-conditions/coronaviruses [accessed on 03 April, 2020].

2. World Health Organization (WHO). Naming the coronavirus disease (COVID-19) and the virus that causes it. Available from: https://www.who.int/ emergencies/diseases/novel-coronavirus-2019/ technical-guidance/naming-the-coronavirus-disease(covid-2019)-and-the-virus-that-causes-it [accessed on 03 April, 2020].

3. Ahmad T, Khan M, Haroon, Musa TH, Nasir S, Hui J, Bonilla-Aldana DK, Rodriguez-Morales AJ. COVID-19: Zoonotic aspects. Travel Med Inf Dis. 2020. DOI: https://doi.org/10.1016/j.tmaid.2020.101607. [Epub ahead of print].

4. Coronavirus COVID-19 Global Cases by the Center for System Science and Engineering (CSSE) at John Hopkins University. Available from: https://gisanddata. maps.arcgis.com/apps/opsdashboard/index.html\#/ bda7594740fd40299423467b48e9ecf6 [accessed on 23 April, 2020].

5. Ahmad T, Khan M, Khan FM, Hui J. Are we ready for the new fatal Coronavirus: scenario of Pakistan? Hum Vacc Immunother. 2020. DOI: https://doi.org/10.108 0/21645515.2020.1724000. [Epub ahead of print]. 